\title{
When morphine does not work
}

\section{Marie Fallon}

Published online: 29 May 2008

(C) Springer-Verlag 2008

\section{Erratum to: Support Care Cancer}

\section{DOI 10.1007/s00520-008-0402-8}

The Legend of Fig. 2 was incorrect. The revised version is given here.

Fig. 2 Brain and spinal cord communication (personal communication from Prof Anthony Dickenson)

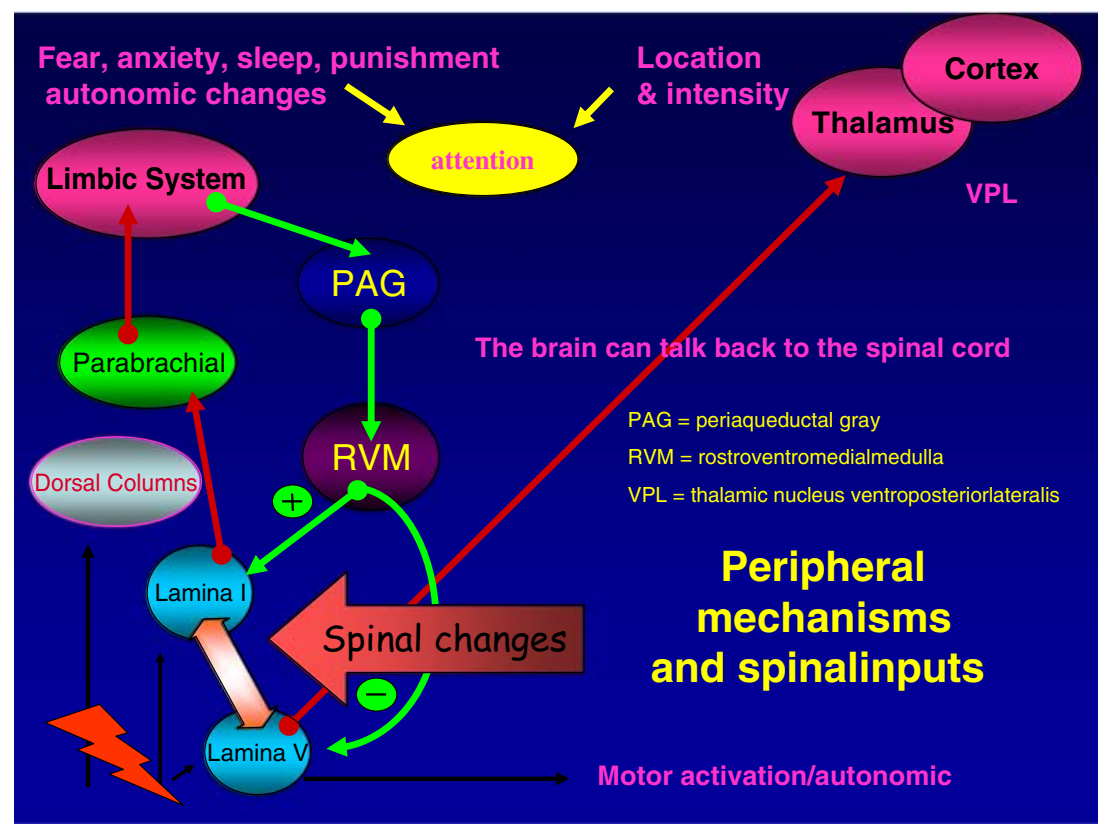

The online version of this article can be found at http://dx.doi.org/ 10.1007/s00520-008-0402-8.

M. Fallon $(\bowtie)$

Edinburgh Cancer Research Centre, Western General Hospital,

University of Edinburgh,

Crewe Road,

Edinburgh EH4 2XR, UK

e-mail: Marie.Fallon@ed.ac.uk 